\title{
Zinc Sulfide Nanoparticle-decorated Fibre Mesh to Enable Localized H2S-amplified Chemotherapy
}

DOI:

10.1039/D0CC00763C

Document Version

Accepted author manuscript

Link to publication record in Manchester Research Explorer

\section{Citation for published version (APA):}

Wang, G., Cen, D., Ren, Z., Wang, Y., Cai, X., Chen, X., Li, X., Best, S. M., \& Han, G. (2020). Zinc Sulfide Nanoparticle-decorated Fibre Mesh to Enable Localized H2S-amplified Chemotherapy. Chemical Communications, 56(31), 4304-4307. https://doi.org/10.1039/D0CC00763C

\section{Published in:}

Chemical Communications

\section{Citing this paper}

Please note that where the full-text provided on Manchester Research Explorer is the Author Accepted Manuscript or Proof version this may differ from the final Published version. If citing, it is advised that you check and use the publisher's definitive version.

\section{General rights}

Copyright and moral rights for the publications made accessible in the Research Explorer are retained by the authors and/or other copyright owners and it is a condition of accessing publications that users recognise and abide by the legal requirements associated with these rights.

\section{Takedown policy}

If you believe that this document breaches copyright please refer to the University of Manchester's Takedown Procedures [http://man.ac.uk/04Y6Bo] or contact uml.scholarlycommunications@manchester.ac.uk providing relevant details, so we can investigate your claim.

\section{OPEN ACCESS}




\section{COMMUNICATION}

\section{Zinc Sulfide Nanoparticle-decorated Fibre Mesh to Enable Localized $\mathrm{H}_{2} \mathrm{~S}$-amplified Chemotherapy}

Received 00th January 20xx, Accepted 00th January 20xx

DOI: $10.1039 / x 0 x \times 00000 x$
Gang Wang ${ }^{\dagger a}$, Dong Cen ${ }^{\text {tb }}$, Zhaohui Ren ${ }^{a}$, Yifan Wang ${ }^{b}$, Xiujun Cai ${ }^{b}$, Xiaohui Chen ${ }^{c}$, Xiang Li *a, Serena Best ${ }^{d}$, Gaorong Han *a
For the first time, we report the design and fabrication of a $\mathrm{ZnS}$ nanoparticle-decorated silica fibre mesh $\left(\mathrm{ZnS@SiO}_{2}\right)$ for localized $\mathrm{H}_{2} \mathrm{~S}$-amplified chemotherapy. With incorporation of DOX, implanted ZnS@SiO ${ }_{2}$ fibres enable sufficient on-site drug dosage and intracellular $\mathrm{H}_{2} \mathrm{~S}$ content, inducing significant in vitro and in vivo tumour inhibition.

While current systemic drug delivery systems (SDDSs) for chemotherapy still face challenges such as burst drug release, low targeting efficiency and inevitable clearance during circulation ${ }^{1,2}$. Localized drug delivery systems (LDDSs), in forms of films, hydrogels, microarrays, rods or drug-eluting wafers, have been developed for targeted chemotherapy 3, 4 Electrospun fibres offer the potential for superior performance in localized chemotherapy due to their unique properties such as high surface area, flexibility and so on ${ }^{5-7}$. Additional benefits include sustained and continuous release of chemotherapeutic drugs, providing a high local drug concentration at the tumour site while maintaining a low drug level in the biological system. For this reason, intensive research has been carried out on fibre-based LDDSs for chemotherapy ${ }^{1}$, and recently there was a move towards drug-loaded nanoparticle-fibre assemblies, in which nanoparticles can be taken-up by cancer cells, underwent intracellular drug release. Meanwhile, there has been rapid

State Key Laboratory of Silicon Materials, School of Materials Science and Engineering, Zhejiang University, 310027, China.E-mail: xiang.li@zju.edu.cn; hgr@zju.edu.cn

b. Department of General Surgery, Institute of Minimally Invasive Surgery, Sir Run Run Shaw Hospital, College of Medicine, Zhejiang University, 310016, China c. Division of Dentistry, School of Medical Sciences, The University of Manchester, UK, Manchester, M13 9PL, UK

d. Department of Materials Science and Metallurgy, University of Cambridge, Cambridge CB3 OFS, UK

+ Authors with equal contribution.

Electronic Supplementary Information (ESI) available: $\mathrm{N}_{2}$ absorption and desorption isotherm curves of $\mathrm{SiO}_{2}$ fibres and $\mathrm{ZnS} @ \mathrm{SiO}_{2}$ fibres. TEM images of $\mathrm{ZnS}$ nanoparticles

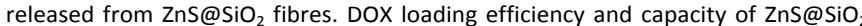
fibres. SEM images of $\mathrm{ZnS} @ \mathrm{SiO}_{2}$ fibres after incubation with PBS solution at $\mathrm{pH}=5.4$ for different time. Bright field images of Huh7 cells after incubation with various samples at $\mathrm{pH}=6.0$ for $12 \mathrm{~h}$. Photographs of representative mice after treatment. See DOI: $10.1039 / x 0 x x 00000 x$ advances in nanomedicine and nanotechnology for more efficient anticancer purposes. Among these emerging modalities, gas therapy has been explored utilizing the generation of therapeutic gases ${ }^{8}$ such as nitric oxide (NO) ${ }^{9}$, carbon monoxide $(\mathrm{CO})^{10}$, hydrogen $\left(\mathrm{H}_{2}\right)^{11}$ and hydrogen sulfide $\left(\mathrm{H}_{2} \mathrm{~S}\right)^{12,13}$ to induce cell death. As the third gas transmitter after $\mathrm{NO}$ and $\mathrm{CO}{ }^{14} . \mathrm{H}_{2} \mathrm{~S}$ can be generated endogenously by the catalysis of $\mathrm{H}_{2} \mathrm{~S}$-producing enzymes ${ }^{15}$. Endogenous or low levels of $\mathrm{H}_{2} \mathrm{~S}$ may lead to pro-cancer effects while the presence of high $\mathrm{H}_{2} \mathrm{~S}$ levels may induce cancer inhibition ${ }^{16}$. Interestingly, studies also suggested that excessive $\mathrm{H}_{2} \mathrm{~S}$ can increase the oxidative stress build-up in cancer cells by suppression of the enzyme catalase (CAT) ${ }^{17}$. In addition, $\mathrm{ZnS}$ can actively react with $\mathrm{H}^{+}$in the acid environment, and thus offers the potential for effective $\mathrm{H}_{2} \mathrm{~S}$ generation ${ }^{18,19}$. Meanwhile, doxorubicin (DOX), a broadspectrum drug used in chemotherapy, could also induce the generation of reactive oxygen species (ROS) besides its capability in causing cancer cell DNA dysfunction ${ }^{20}$. The suppression of CAT leads to over-production of $\mathrm{H}_{2} \mathrm{O}_{2}$, increasing the ROS level and promoting DNA damage and cell necrosis ${ }^{21}$. Therefore, it would be logical to combine DOX and $\mathrm{H}_{2} \mathrm{~S}$ gas in one therapeutic platform to achieve $\mathrm{H}_{2} \mathrm{~S}$-enhanced chemotherapy. However, to the best of our knowledge, no such investigation has yet been reported.

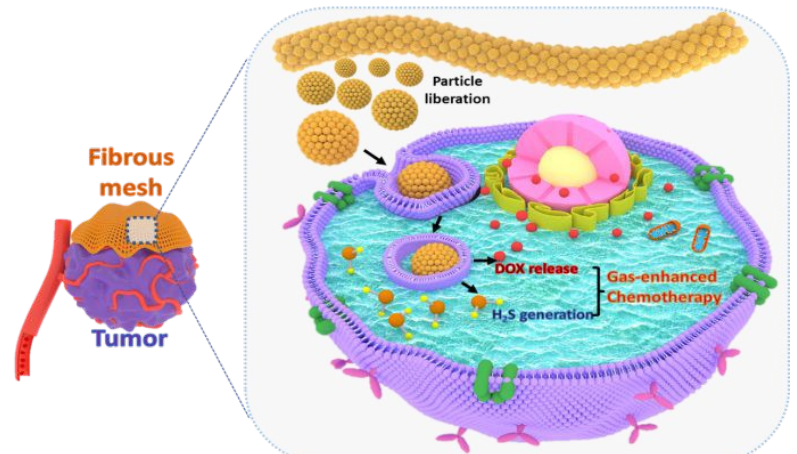

Fig. 1 Schematic illustration of DOX-ZnS@ $\mathrm{SiO}_{2}$ fibrous mesh for localized $\mathrm{H}_{2} \mathrm{~S}$-amplified chemotherapy. 

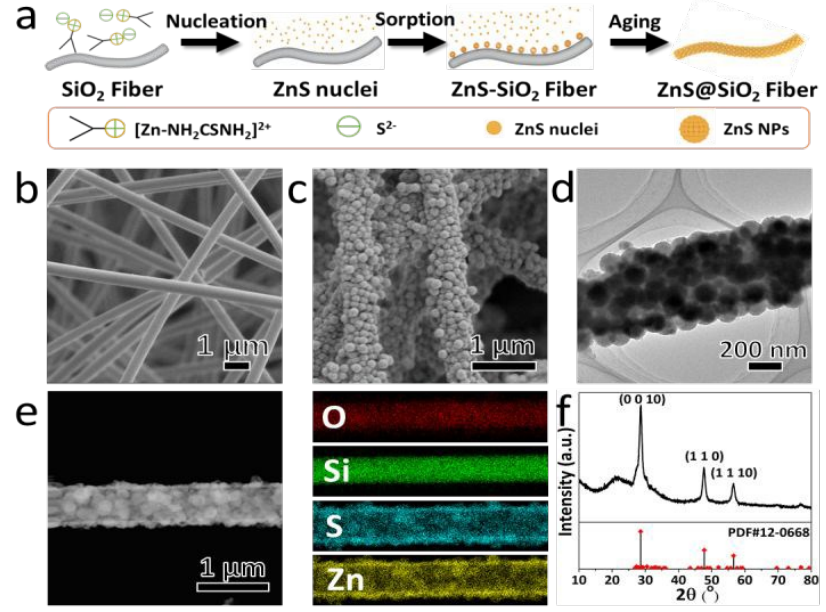

Fig. 2 (a) Schematic illustration of the formation mechanism of $\mathrm{ZnS@SiO}$ fibres; SEM images of (b) as-spun $\mathrm{SiO}_{2}$ and (c) ZnS@SiO ${ }_{2}$ fibres; (d) TEM image, (e) EDS elemental mapping and (f) XRD pattern of $\mathrm{ZnS@SiO} 2$ fibres.

In the present study, we aimed to develop an enhanced chemotherapy platform combining the benefits of both gas therapy and localized drug release, comprising doxorubicin (DOX) loaded ZnS nanoparticles assembled silica fibres (DOX$\mathrm{ZnS} @ \mathrm{SiO}_{2}$ ) (as shown in Fig. 1). The in vitro and in vivo anticancer performance of the DOX-ZnS@SiO ${ }_{2}$ fibrous mesh was also revealed.

$\mathrm{ZnS@SiO}$. composite fibres were synthesized via hydrothermal growth of ZnS nanoparticles on the surface of silica nanofibres (procedure as demonstrated in Fig. 2a). A flexible silica fibrous membrane was prepared via electrospinning and subsequent heat treatment according to a modified sol-gel method reported previously ${ }^{22}$. After calcination at $800^{\circ} \mathrm{C}$ for $3 \mathrm{~h}$, the as-prepared $\mathrm{SiO}_{2}$ nanofibres presented a fibrous texture and smooth surface morphology (Fig. 2b). Flexible silica nanofibres with negative charged surface and inactivity during hydrothermal process enabled the assembly of ZnS nanoparticles ${ }^{23}$.

Following the hydrothermal synthesis of ZnS nanoparticles reported previously ${ }^{24}$, ZnS nuclei formed in the precursor solution, and were subsequently absorbed and grew on the surface of silica fibres. ZnS nanoparticles with an average diameter of $\sim 110 \mathrm{~nm}$ were uniformly assembled on the surface of silica fibres (Fig. 2c, 2d). In consequence, the diameter of the composite fibres increased from $510 \mathrm{~nm}$ to $720 \mathrm{~nm}$, and a slight decrease in surface area was observed (Fig. S1). ZnS nanoparticles liberated from $\mathrm{ZnS} @ \mathrm{SiO}_{2}$ fibres were composed of nanocrystals, which increased the pore size of the composite fibres (Fig. S2). Meanwhile, element mapping images showed a homogeneous distribution of sulphur and zinc in $\mathrm{ZnS@SiO}_{2}$ composite fibres (Fig. 2e), confirming the successful growth of ZnS nanoparticles on the surface of silica nanofibres. A representative XRD pattern of the as-prepared $\mathrm{ZnS@SiO}_{2}$ composite fibres is shown in Fig. 2f. The broad peak appeared from $15^{\circ}$ to $35^{\circ}$ on the diffraction pattern was ascribed to $\mathrm{SiO}_{2}$ due to its amorphous nature. Three main diffraction peaks are visible and these match well with the primary peaks of the
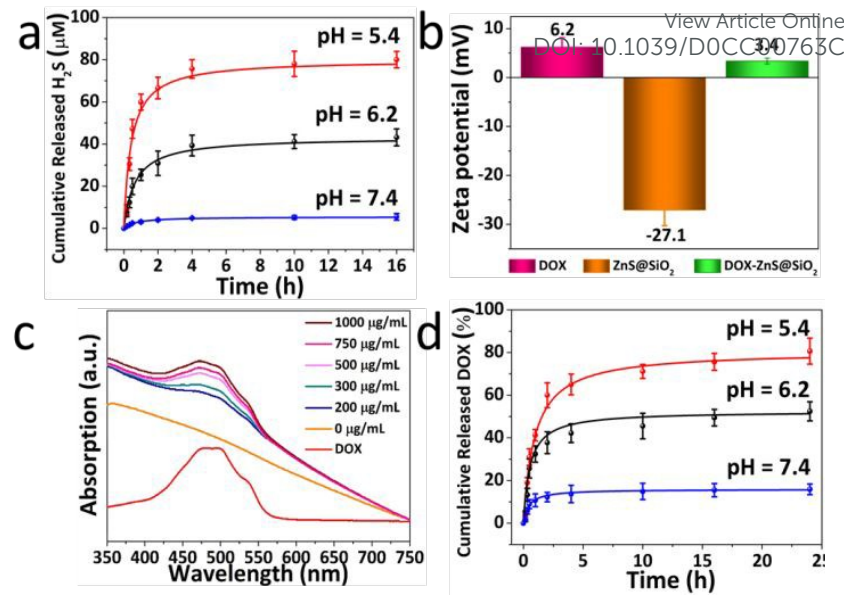

Fig. 3 (a) Cumulative $\mathrm{H}_{2} \mathrm{~S}$ gas release of $\mathrm{ZnS@S \textrm {O } _ { 2 }}$ fibrous mesh in solutions different $\mathrm{pH}$; (b) Zeta potentials of DOX, $\mathrm{ZnS} @ \mathrm{SiO}_{2}$ fibres and DOX-ZnS@SiO 2 fibres; (c) UV-Vis spectra of DOX solution, $\mathrm{ZnS} @ \mathrm{SiO}_{2}$ fibres and DOX$\mathrm{ZnS} @ \mathrm{SiO}_{2}$ fibres loaded in DOX solutions with different concentrations; (d) Cumulative DOX release profile of DOX$\mathrm{ZnS} @ \mathrm{SiO}_{2}$ fibres in PBS at different $\mathrm{pH}$ values.

characteristic diffraction patterns of wurtzite ZnS (PDF\# 120688), indicating the assembly of $\mathrm{ZnS}$ on the surface of $\mathrm{SiO}_{2}$ nanofibres. The $\mathrm{ZnS} @ \mathrm{SiO}_{2}$ composite fibres synthesized demonstrated a high degree of ZnS nanoparticle loading, and this laid the foundation for the construction of a $\mathrm{H}_{2} \mathrm{~S}$-enhanced chemotherapy platform.

The in vitro $\mathrm{H}_{2} \mathrm{~S}$ gas release profile of the $\mathrm{ZnS} @ \mathrm{SiO}_{2}$ composite fibres was investigated at different $\mathrm{pH}$ values. The concentration of $\mathrm{H}_{2} \mathrm{~S}$ gas in aqueous solution was measured using a spectrophotometric procedure and quantified with a standard curve (Fig. S3). Under neutral conditions, the mean cumulative concentration of $\mathrm{H}_{2} \mathrm{~S}$ gas was $4.9 \mu \mathrm{M}$ after the first $4 \mathrm{~h}$ and $5.5 \mu \mathrm{M}$ after $16 \mathrm{~h}$. In comparison, under acidic conditions (designed to simulate the mild acid tumour microenvironment) the mean cumulative concentration of $\mathrm{H}_{2} \mathrm{~S}$ after $16 \mathrm{~h}$ reached $43.3 \mu \mathrm{M}$ and $80.6 \mu \mathrm{M}$ at $\mathrm{pH}=6.2$ and $\mathrm{pH}=$ 5.4, respectively (Fig. 3a). These results demonstrate that, in the presence of hydrogen ions $\left(\mathrm{H}^{+}\right)$, ZnS nanoparticles on the surface of $\mathrm{ZnS@SiO} 2$ composite fibres could react with $\mathrm{H}^{+}$to produce $\mathrm{H}_{2} \mathrm{~S}$ gas which is a prerequisite for $\mathrm{H}_{2} \mathrm{~S}$-enhanced chemotherapy.

Encouraged by the favourable structure of $\mathrm{ZnS} @ \mathrm{SiO}_{2}$ fibres, DOX was used as a model drug and loaded on the fibrous mesh for chemotherapy. As shown in Fig. 3b, the mean zeta potentials of DOX and ZnS@SiO $\mathrm{Sibres}_{2}$ were $6.2 \mathrm{mV}$ and $-27.1 \mathrm{mV}$, implying that it is feasible to load DOX by electrostatic absorption. After drug loading, the mean zeta potential of DOX$\mathrm{ZnS@SiO} 2$ fibres became positive $(3.4 \mathrm{mV})$, indicating the successful loading of DOX. UV-Vis spectra of DOX loaded ZnS@SiO ${ }_{2}$ composite fibres (Fig. 3c) revealed that the DOX loading capacity increased with the increasing DOX concentration, while the loading efficiency decreased sharply (Fig. S5). Considering the adverse effects and therapeutic effects ${ }^{25}$, the loading concentration of DOX solution was set at $100 \mu \mathrm{g} / \mathrm{ml}$ for subsequent studies. 


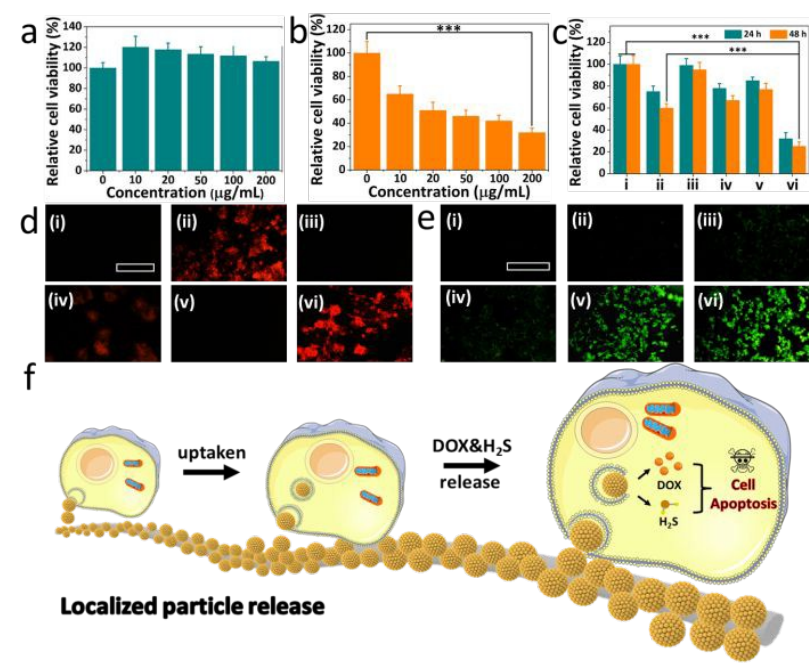

Fig. 4 Relative viability of (a) 7702 cells incubated with $\mathrm{ZnS} @ \mathrm{SiO}_{2}$ fibres for $24 \mathrm{~h}$ at $\mathrm{pH}=7.4$ and (b) Huh7 cancer cells incubated with DOX-ZnS@SiO ${ }_{2}$ fibres with different concentrations at pH = 6.0 for $24 \mathrm{~h}$; (c) Relative cell viability, (d) DOX fluorescent images and (e) WSP-1 fluorescent images of Huh7 cancer cells incubated with (i) pure culture medium, (ii) DOX $(4.5 \mu \mathrm{g} / \mathrm{mL}$ ), (iii) $\mathrm{ZnS@SiO}$ fibres $(100 \mu \mathrm{g} / \mathrm{mL})$ at $\mathrm{pH}=7.4$, (iv) DOX-ZnS@SiO ${ }_{2}$ fibres $(100$ $\mu \mathrm{g} / \mathrm{mL}$ ) at $\mathrm{pH}=7.4$, (v) $\mathrm{ZnS} @ \mathrm{SiO}_{2}$ fibres at $\mathrm{pH}=6.0$, (vi) DOX$\mathrm{ZnS@SiO}{ }_{2}$ fibres at $\mathrm{pH}=6.0$. Scale Bar: $100 \mu \mathrm{m}$; (f) Mechanism illustration of the $\mathrm{H}_{2} \mathrm{~S}$-enhanced anticancer effect achieved by DOX-ZnS@SiO ${ }_{2}$ fibres.

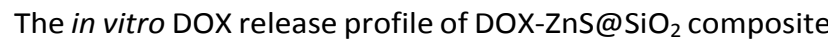
fibres was investigated (Fig. 3d). At pH $=7.4$, only $15.9 \%$ of DOX was released in the initial $24 \mathrm{~h}$, which could be attributed to free diffusion of DOX in the composite fibres. In contrast, $80.6 \%$ and $52.4 \%$ of DOX in the composite fibres were released in the same period at $\mathrm{pH}=5.4$ and $\mathrm{pH}=6.2$, respectively. There are two reasons for the $\mathrm{pH}$-dependent release profile. As discussed previously, under acidic conditions, ZnS nanoparticles react with $\mathrm{H}^{+}$ions to release $\mathrm{H}_{2} \mathrm{~S}$ gas. As the reaction proceeds, it is suggested that the $\mathrm{ZnS}$ nanoparticles are liberated from silica fibres (Fig. S6). The hydrodynamic diameter of the release ZnS nanoparticles was $\sim 190 \mathrm{~nm}$ with polymer dispersion index of 0.289 (Fig. S7). Moreover, $\mathrm{H}^{+}$ions are likely to destroy the electrostatic interaction between $\mathrm{ZnS}$ nanoparticles and DOX molecules, also accelerating the drug-release.

The in vitro performance of DOX-ZnS@ $\mathrm{SiO}_{2}$ composite fibres was investigated using Human HL-7702 liver cells and Human Huh-7 liver cancer cells. As shown in Fig. 4a, no clear toxicity was observed when the concentration of $\mathrm{ZnS} @ \mathrm{SiO}_{2}$ fibre was increased up to $200 \mu \mathrm{g} / \mathrm{ml}$, indicating its biocompatible. This observation was thought to be due to the fact that, under neutral conditions, the concentration of $\mathrm{H}_{2} \mathrm{~S}$ released from $\mathrm{ZnS@SiO}$ fibres is not sufficiently high to induce normal cells death. To uncover the anticancer performance, Huh7 liver cancer cells were incubated with DOX-ZnS@SiO ${ }_{2}$ fibres under different concentrations. The $\mathrm{pH}$ of the culture media was adjusted to 6.0 by adding hydrochloric acid ${ }^{26}$. Incubation for 24 $\mathrm{h}$ at concentration of DOX-ZnS@ $\mathrm{SiO}_{2}$ fibres up to $200 \mu \mathrm{g} / \mathrm{ml}$ resulted in $68.2 \%$ Huh7 cell death and the IC50 value was $\sim 23.6 \mu \mathrm{g} / \mathrm{ml}$ (Fig. 4b). To further investigate the underlying

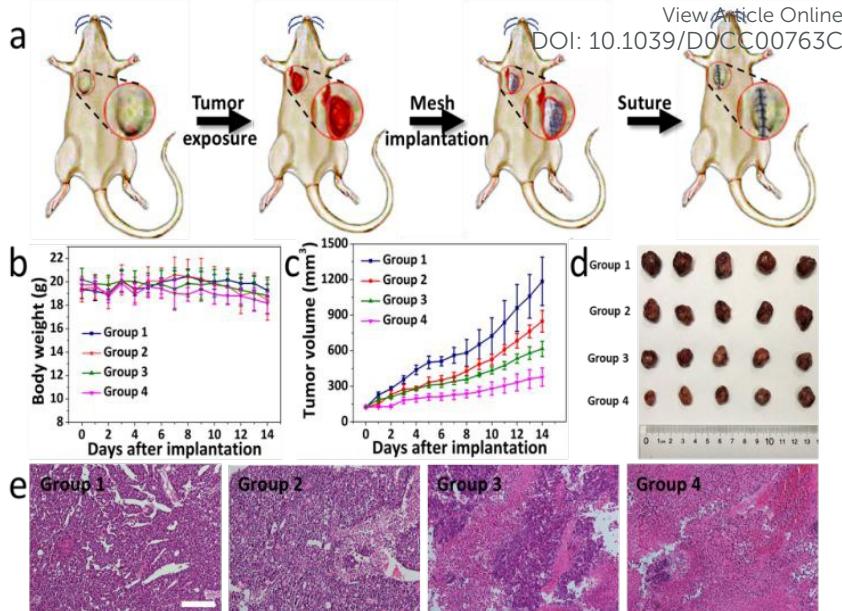

Fig. 5 (a) Schematic illustration of the implantation procedures

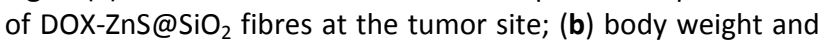
(c) tumor volume variations of mice after various treatments $(n=5)$; Digital photographs of (d) representative tumors and (e) $\mathrm{H} \& \mathrm{E}$-stained tumor slices collected from different groups of mice after 14-day treatment. Scale bar: $1000 \mu \mathrm{m}$

influence of $\mathrm{H}_{2} \mathrm{~S}$ gas induced, the following systems were used to treat Huh7 cells: (i) pure culture medium; (ii) culture medium containing DOX of $4.5 \mu \mathrm{g} / \mathrm{mL}$; (iii) ZnS@SiO ${ }_{2}$ fibres of $100 \mu \mathrm{g} / \mathrm{mL}$ at neutral pH; (iv) DOX-ZnS@SiO ${ }_{2}$ fibres of $100 \mu \mathrm{g} / \mathrm{mL}$ at neutral $\mathrm{pH}$; (v) ZnS@SiO $\mathrm{Z}_{2}$ fibres of $100 \mu \mathrm{g} / \mathrm{mL}$ at $\mathrm{pH}=6.0$; (vi) DOX$\mathrm{ZnS@SiO}{ }_{2}$ fibres of $100 \mu \mathrm{g} / \mathrm{mL}$ at $\mathrm{pH}=6.0$. The concentration of DOX in Group (ii) maintained at the same level as that for the DOX-ZnS@SiO ${ }_{2}$ fibres in Group (iv) and Group (vi). However, it should be noted that this is relatively low in comparison with that reported in DOX chemotherapy ${ }^{23}$. As shown in Fig. 4c, after $48 \mathrm{~h}$ incubation, for free DOX alone (ii) only $39.5 \%$ Huh7 cell death occurred, and $\mathrm{ZnS@SiO} 2$ fibres induced virtually no cell necrosis under neutral $\mathrm{pH}$ condition. In comparison, although certain $\mathrm{H}_{2} \mathrm{~S}$ gas may potentially release extracellularly, the cell viability (Group v) decreased to $\sim 77.1 \%$ after incubation with $\mathrm{ZnS} @ \mathrm{SiO}_{2}$ fibres at $\mathrm{pH}=6.0$ for $48 \mathrm{~h}$. This could be attributed to the release of high concentrations of on-site $\mathrm{H}_{2} \mathrm{~S}$ gas in the acidic environment, consequently inducing cell death. The cell viability of DOX-ZnS@SiO ${ }_{2}$ fibres decreased from 68.6\% (Group iv) to $\sim 24.8 \%$ (Group vi) after $48 \mathrm{~h}$ when the culture medium varied from the neutral to $\mathrm{pH}=6$, implying its amplified in vitro anticancer performance by the $\mathrm{H}_{2} \mathrm{~S}$ induced in an acid condition.

The examination using flow cytometry indicates that the tumour cell can effectively uptake ZnS nanoparticles released from the composite fibres during the incubation for $24 \mathrm{~h}$ (Fig. S8). The synergistic anticancer performance of the DOX$\mathrm{ZnS} @ \mathrm{SiO}_{2}$ fibre mesh, was investigated by evaluating the intracellular presence of DOX and $\mathrm{H}_{2} \mathrm{~S}$. Under excitation at 480 $\mathrm{nm}$, DOX presents intense red fluorescence at $590 \mathrm{~nm}$. After 12 $\mathrm{h}$ incubation, as expected, Huh7 cells treated with the DOX$\mathrm{ZnS} @ \mathrm{SiO}_{2}$ fibrous mesh at $\mathrm{pH}=6.0$ showed higher intracellular level of DOX even than those treated with pure DOX (Fig. 4d, Fig. S9). This may be associated with the continuous release of DOX from the DOX loaded fibres under acidic conditions, while pure DOX was consumed rapidly during the incubation process. In addition, using WSP-1 as a probe, cells incubated with 
$\mathrm{ZnS@ \textrm {SiO } _ { 2 } \text { and DOX-ZnS@SiO }}$ fibres encountered significant $\mathrm{H}_{2} \mathrm{~S}$ gas release under acidic conditions (Fig. 4e, Fig. S10). On the contrary, no $\mathrm{H}_{2} \mathrm{~S}$ gas was released under neutral $\mathrm{pH}$ conditions.

Based on the in vitro findings, it is proposed that, under an acidic condition, DOX-loaded ZnS nanoparticles on the surface of silica fibres are released and taken-up by Huh7 cells. Subsequently, both DOX and $\mathrm{H}_{2} \mathrm{~S}$ gas are released intracellularly. The $\mathrm{H}_{2} \mathrm{~S}$ at the certain concentration may amplify the anticancer efficacy of DOX (Fig. 4f). This is attributed to that $\mathrm{H}_{2} \mathrm{~S}$ gas can effectively suppress the activity of catalase which is the key enzyme for $\mathrm{H}_{2} \mathrm{O}_{2}$ decomposition ${ }^{26}$. Thus, increased oxidative stress at the tumour site leads to cell apoptosis and improved efficacy of DOX.

The in vivo therapeutic performance of DOX-ZnS@SiO ${ }_{2}$ fibre mesh was investigated using a Huh7 mouse tumour model. $\mathrm{ZnS@SiO} 2$ fibres and DOX-ZnS@SiO ${ }_{2}$ fibres were implanted in the tumour site via minimally invasive surgery, respectively (Fig. 5a). Compared with the control group (Group 1), no clear weight variation was observed in the mice treated with intratumorally injected DOX (Group 3), ZnS@SiO 2 fibres (Group 2) and DOX-ZnS@SiO ${ }_{2}$ fibres (Group 4), indicating that there was no acute toxicity associated with the treatment systems (Fig. 5b). On day 14, the tumour progression of mice treated with low dosage of DOX was partially inhibited (Fig. 5c). Mice treated with ZnS@SiO ${ }_{2}$ fibres showed considerable tumour suppression compared with the control group (Fig. S11 and Fig. 5d).

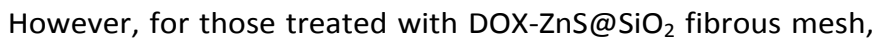
the tumour sizes shrank after 14 days treatment. Furthermore, H\&E-stained microscopy slices of tutors indicated that the tumour tissues treated with DOX-ZnS@SiO ${ }_{2}$ fibres were more seriously damaged than those with DOX only (Fig. 5e). However, in the control groups with ZnS@SiO ${ }_{2}$ fibres, the tumour tissues retained their normal pathology. Overall, the in vivo results suggest that the use of a DOX-ZnS@SiO ${ }_{2}$ fibre mesh offers an effectively enhanced chemotherapeutic efficacy.

In this study, for the first time, a fibrous silica mesh with an active surface comprising $\mathrm{ZnS}$ nanoparticles is synthesized to enable $\mathrm{H}_{2} \mathrm{~S}$ gas combined chemotherapy in a localized manner. $\mathrm{ZnS}$ nanoparticles, used as a $\mathrm{H}_{2} \mathrm{~S}$-generating donor, were assembled on the surface of electrospun $\mathrm{SiO}_{2}$ nanofibres. Under acidic conditions, $\mathrm{ZnS} @ \mathrm{SiO}_{2}$ nanofibres released $\mathrm{H}_{2} \mathrm{~S}$ gas due to the reaction of $\mathrm{ZnS}$ with $\mathrm{H}^{+}$ions. The cumulative $\mathrm{H}_{2} \mathrm{~S}$ gas concentration was up to $80.63 \mu \mathrm{M}$ at $\mathrm{pH}=5.4$, which was significantly higher than that in normal tissue. $\mathrm{ZnS}$ nanoparticles may liberate from $\mathrm{ZnS@SiO} 2$ fibres in the presence of $\mathrm{H}^{+}$ions and can be effectively taken-up by cancer cells. The DOX loaded $\mathrm{ZnS@SiO}$ fibres exhibited a pH-dependent drug release profile. The in vitro study demonstrated that, due to the combined effects for intracellular DOX and $\mathrm{H}_{2} \mathrm{~S}$ induction, DOX-ZnS@ $\mathrm{SiO}_{2}$ fibres had exceptional in vitro and in vivo performance when

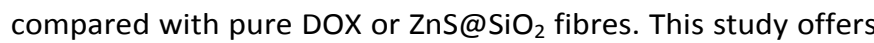
a distinctive approach to materials design by combining fibres and particles for LDDSs and will pave the way not only for enhanced chemotherapy, but also other modalities of ROS based cancer treatment.

\section{Acknowledgement}

View Article Online DOI: 10.1039/DOCC00763C This work was financially supported by National Nature Science Foundation of China (51672247), ZJU-Hangzhou Global Scientific and Technological Innovation Center, '111' Program funded by Education Ministry of China and Sate Bureau of Foreign Experts Affairs (B16043), Fundamental Research Funds for the Central Universities (2019XZZX005-3-01) and Provincial Key Research Program of Zhejiang Province (2020C04005).

\section{Conflicts of interest}

There are no conflicts to declare.

\section{Notes and references}

1 Y. Fu, X. Li, Z. Ren, C. Mao and G. Han, Small, 2018, 14, 1801183.

2 H.-K. Yang, J.-F. Bao, L. Mo, et. al., RSC Adv., 2017, 7, 2109321106.

3 L. Polakova, J. Sirc, R. Hobzova, A. I. Cocarta and E. Hermankova, International journal of pharmaceutics, 2019, 558, 268-283.

4 J. B. Wolinsky, Y. L. Colson and M. W. Grinstaff, J. Controlled. Release, 2012, 159, 14-26.

5 J. Xue, J. Xie, W. Liu and Y. Xia, Accounts Chem Res, 2017, 50, 1976-1987.

6 S. Jiang, L. P. Lv, K. Landfester and D. Crespy, Accounts Chem Res, 2016, 49, 816-823.

7 L. S. Nair, S. Bhattacharyya and C. T. Laurencin, Expert Opin Biol Th, 2004, 4, 659-668.

8 H. Lin, Y. Chen and J. Shi, Chem Soc Rev, 2018, 47, 1938-1958.

9 X. Zhang, G. Tian, W. Yin, et. al., Adv. Funct. Mater., 2015, 25, 3049-3056.

10 Y. Wang, Z. Liu, H. Wang, et. al., Acta Biomater, 2019, 92, 241253.

11 I. Ohsawa, M. Ishikawa, K. Takahashi, et. al., Nature Med, 2007, 13, 688-694.

12 G. L. Bannenberg and H. L. Vieira, Expert Opin Ther Pat, 2009, 19, 663-682.

13 Z. W. Lee, J. Zhou, C. S. Chen, Y. Zhao, C. H. Tan, L. Li, P. K. Moore and L. W. Deng, PloS one, 2011, 6, e21077.

14 K. Abe, H. Kimura, J Neurosci, 1996, 16, 1066-1071.

15 B. L. Predmore, D. J. Lefer and G. Gojon, Antioxid \& Redox Sign, 2012, 17, 119-140.

16 M. R. Hellmich, C. Coletta, C. Chao and C. Szabo, Antioxid \& Redox Sign, 2015, 22, 424-448.

17 M. A. Eghbal, P. S. Pennefather and P. J. O'Brien, Toxicology, 2004, 203, 69-76.

18 S. Licht, J. Electrochem. Soc., 1988, 135, 2971-2975.

19 S. K. Dash, T. Ghosh, S. Roy, S. Chattopadhyay and D. Das, Journal of applied toxicology : JAT, 2014, 34, 1130-1144.

20 Y. Chen, P. Jungsuwadee, M. Vore, D. A. Butterfield and D. K. St Clair, Molecular interventions, 2007, 7, 147-156.

21 M. S. Attene-Ramos, E. D. Wagner, H. R. Gaskins and M. J. Plewa, Molecular cancer research : MCR, 2007, 5, 455-459.

22 X. Mao, Y. Si, Y. C. Chen, L. P. Yang, F. Zhao, B. Ding and J. Y. Yu, RSC Adv., 2012, 2, 12216-12223.

23 G. Wang, Y. Fu, Z. Ren, J. Huang, S. Best, X. Li and G. Han, Chem Commun, 2018, 54, 6324-6327.

24 L. Zhang, R. Dong, Z. Zhu et. al., Sensor Actuat B-Chem, 2017, 245, 112-121.

25 W. Zhang, Z. Guo, D. Huang et. al., Biomaterials, 2011, 32, 85558561.

26 C. Xie, D. Cen, Z. Ren et. al., Advanced science, 2020, 1903512. 